\title{
Effect of Ultrasound Treatment on the Sterilization and Quality of Cucurbita pepo
}

\author{
Suo Guanwen ${ }^{1}$, Cai Meijuan ${ }^{1}$, Zhou Chunli $^{\mathrm{a} 1}, \mathrm{Su}_{\mathrm{Wei}}{ }^{1}$, Hu Xueyan ${ }^{1}$ \\ ${ }^{1}$ (School of Life Science, Jiangxi Science \&Technology Normal University (Nanchang 330013)
}

\begin{abstract}
The influence of ultrasonic technology on the sterilization effect and quality of Cucurbita pepo juice were studied in this paper. The sterilization rate under conditions of control $100 \mathrm{~W}, 200 \mathrm{~W}, 300 \mathrm{~W}$ ultrasonic, color difference, total chlorophyll content, $\mathrm{pH}$ changes on juice Cucurbita pepo were determined. The results showed that the total color difference, browning index, whiteness index and total chlorophyll content of the juice had significant changes, while the $\mathrm{pH}$ had no significant changes. Ultrasonic has a certain influence on the sterilization effect of Cucurbita pepo, and ultrasonic treatment is helpful to maintain the quality of pumpkin juice in a certain range. In the future, it is hoped that ultrasonic technology will combine with other technologies to achieve commercial sterility while minimizing the loss of quality in Cucurbita pepo.
\end{abstract}

\section{Introduction}

Cucurbita pepo, commonly known as zucchini, is a common vegetable on the family table, rich in nutritional value, deeply loved by people. Pumpkin pulp sweet and mild, are rich in polysaccharides, carotenoids, pectin, vitamins $(\mathrm{C}, \mathrm{E}, \mathrm{K}$, thiamine riboflavin and pyridoxine), amino acids, minerals (Fe, $\mathrm{Mg}, \mathrm{K}, \mathrm{P}, \mathrm{Se}$ ), dietary fiber, phenolic compounds (flavonoids, phenolic acids) and other substances beneficial to human health, so which has high nutritional and medicinal value ${ }^{[1-7]}$. Cucurbita pepo in the past use of stacking, cellaring, storage and other ways, there are certain requirements for space, temperature, humidity, general requirements need ventilation, temperature is not too high or too low, higher than the set temperature pumpkin easy to rot, less than $0{ }^{\circ} \mathrm{C}$ prone to cold damage.

Maintain asepsis can extend the storage period of Cucurbita pepo in the processing, storage, transportation. The high temperature of the traditional thermal processing sterilization method will have a certain impact on the quality of pumpkin, while the Ultrasonic treatment can reduce the loss of nutritional quality of Cucurbita pepo. Ultrasonic processing is one of the non-thermal processing technologies to alternative to thermal pasteurization of food products and a new low-cost technology. The mechanism of ultrasonic processing is simple, no chemical residue, high safety, low energy consumption, economic and environmental protection, and product quality deterioration can be ignored ${ }^{[8]}$. Ultrasonic treatment reduces the pathogenic microorganisms of fruit juice, retains the bioactive compounds of fruit juice, and has effects on the color, antioxidant, vitamin C, polysaccharides, pectin, total phenol content and enzyme activity of fruit juice. It has been found in mango juice ${ }^{[9]}$, cranberry juice ${ }^{[10]}$, grapefruit juice ${ }^{[11]}$, orange juice ${ }^{[12]}$, and other relevant literatures have reported. However, there are few studies to evaluate the effect of ultrasonic treatment on pumpkin juice. The aim of this study is to analyze the effects of ultrasonic treatment on pumpkin juice, and to provide a theoretical basis for ultrasonic processing and production of pumpkin juice and development of fruit juice-pumpkin juice combination products.

\section{Materials and methods}

\subsection{Experimental materials}

\subsubsection{Material}

Pumpkin (bought from Lemaijia Supermarket)

\subsubsection{Drugs and reagents}

Drug: NaCl, LB Nutrition Agar, Ethanol, Acetone Reagent:

(1) LB medium, $40 \mathrm{~g}$ nutrient AGAR powder was dissolved in $1000 \mathrm{~mL}$ distilled water, and autoclaved for 15 minutes after packing;

(2) The volume fraction was $80 \%$ acetone, and $80 \mathrm{~mL}$ acetone (analytical pure) was added with distilled water to a constant volume of $100 \mathrm{ml}$;

(3) $0.9 \% \mathrm{NaCl}$ solution, $0.9 \mathrm{~g} \mathrm{NaCl}$ was dissolved in a small amount of distilled water, and then the volume was constant to $3100 \mathrm{ml}$;

(4) $75 \%$ ethanol solution.

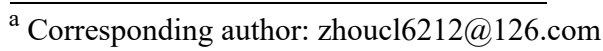




\subsubsection{Experimental equipment}

$15 \mathrm{ml}$ plastic centrifuge tube, $25 \mathrm{ml}$ with calibration test tubes, glass rod, a beaker, taper bottle and a cork, wipe mirror paper, gauze, funnel, sterile liquid gun, $1 \mathrm{ml}$ spear, plate count AGAR, constant temperature incubator, Ultrasonic cell crusher SCIENTZ- II D (Ningbo Xinzhi Biotechnology Co., Ltd.), super clean workbench, juicer (philips), Colori7 color difference meter, ultraviolet spectrophotometer (Shanghai Fine China Technology Co., Ltd.), Shanghai Lei Magi PHS-3C pH tester.

\subsection{Experimental method}

\subsubsection{Pre-treatment of pumpkin}

Clean the Cucurbita pepo, remove the tail, pedicle and fruit pulp, cut into small pieces, and press the juice with a juicer. Divide the pumpkin juice into four parts and put it in a $100 \mathrm{ml}$ brown conical flask, and store it in a refrigerator at $4{ }^{\circ} \mathrm{C}$ for later use.

\subsubsection{Ultrasonic treatment}

Ultrasonic treatment conditions: frequency: $25 \mathrm{~K} \mathrm{~Hz}$; time: $5 \mathrm{~min}$; power: $100 \mathrm{~W}, 200 \mathrm{~W}, 300 \mathrm{~W}$; temperature: $25{ }^{\circ} \mathrm{C}$.

\subsubsection{Measurement of chlorophyll}

The contents of total chlorophyll in Cucurbita pepo were calculated according to method of Arnon ${ }^{[13]}$.

$$
\mathrm{X}=(20.0 \mathrm{D} 663 \mathrm{~nm}+8.02 \mathrm{D} 645 \mathrm{~nm}) \quad 25 / \mathrm{V}
$$

In the formula, $\mathrm{X}$ : total chlorophyll content, $\mu \mathrm{g} / \mathrm{mL}$ fresh weight; V: the volume of pumpkin juice, ml; D663 $\mathrm{nm}$ and D645 nm are respectively $663 \mathrm{~nm}$ and light absorption value at $645 \mathrm{~nm}$.

\subsubsection{Determination of sterilizing rate}

Test method reference GB 4789.2-2016. The bactericidal effect of the Cucurbita pepo treated by ultrasonic is expressed by the bactericidal rate, which is calculated by the formula:

$$
\text { Sterilizing rate }(\%)=\frac{x_{0}-x}{x_{0}} \times 100
$$

in the formula, $X_{0}$ : total number of bacteria before treatment; $X$ : total number of bacteria after treatment

\subsubsection{Determination of color}

For color determination of the treated pumpkin juice, a colorimeter (Color i7) was used. For measure the color changes, the following parameters were determined: $\mathrm{L}^{*}$ (brightness/darkness), $\mathrm{a}^{*}$ (redness/greenness), $\mathrm{b}$ *(yellow ness/blueness), chroma (C), and hue angle (h), total color difference (TCD) and browning index (BI) were expressed according to the following equations ${ }^{[14]}$.

$$
\begin{aligned}
& \mathrm{C}=\left(\mathrm{a}^{* 2}+\mathrm{b}^{* 2}\right)^{1 / 2} \\
& \mathrm{~h}=\tan ^{-1}\left(\mathrm{a}^{*} / \mathrm{b}^{*}\right)
\end{aligned}
$$

$$
\begin{aligned}
& \mathrm{TCD}=\left[(\triangle \mathrm{L})^{2}+(\triangle \mathrm{a})^{2}+(\triangle \mathrm{b})^{2}\right]^{1 / 2} \\
& \mathrm{BI}=100(\mathrm{X}-0.31) \quad(5) \text { in the formula, } \\
& \mathrm{X}=\left(\mathrm{a}^{\left.*+1.75 \mathrm{~L}^{*}\right) /\left(5.645 \mathrm{~L}^{*}+\mathrm{a}^{*}-3.012 \mathrm{~b}^{*}\right)}\right.
\end{aligned}
$$

\subsubsection{Determination of $\mathrm{pH}$}

The $\mathrm{pH}$ value of Cucurbita pepo juice was measured by PHS- $3 \mathrm{C} \mathrm{pH}$ tester.

\subsection{Statistical Analysis}

For the three samples of pumpkin juice in each group. All treatments were carried out in triplicate for each condition and all measurements were done in triplicate. The results were analyzed by Origin 2019 and SPSS 21.

\section{Results and analysis}

\subsection{Influence of ultrasonic technology on the sterilization effect of Cucurbita pepo}

As can be seen from Figure 1, with the increase of ultrasonic power, the sterilization rate of Cucurbita pepo gradually increased, but the sterilization rate was low. In the experiment, the ultrasonic power was low, and the time of $5 \mathrm{~min}$ was short, and the ultrasonic temperature was controlled below $25{ }^{\circ} \mathrm{C}$, which led to the insignificant sterilization effect and failed to reach the state of commercial sterility. Ultrasonic sterilization mechanism is due to its cavitation can have a certain impact on the structure of microbial cells, cavitation makes cells and organelles within the cell, all kinds of substances shock, cell is destroyed and then achieve a sterilization effect ${ }^{[15]}$. It has been found that ultrasound treatment alone is effective in controlling the microbiome (thermophilic bacteria, cryophilic bacteria, and total coliforms), but the combination of heat and ultrasound is more suitable for controlling pathogenic bacteria and spoilage bacteria ${ }^{[15]}$. However, the combination of heat and ultrasound is less effective in controlling pathogenic bacteria and spoilage bacteria. In the future research, it is necessary to adjust the ultrasonic treatment parameters to further explore its sterilization effect.

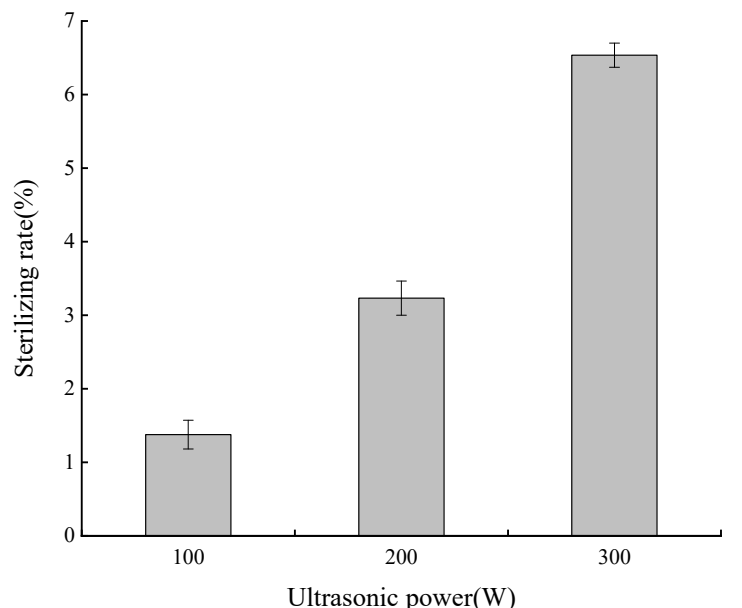

Figure 1. Sterilization rate of Cucurbita pepo juice treated with ultrasound 


\subsection{Influence of ultrasonic technology on color aberration and $\mathrm{PH}$ of Cucurbita pepo}

Table 1. Effects of ultrasound treatment on the color attributes and $\mathrm{PH}$ in the pumpkin juice

\begin{tabular}{ccccc}
\hline & Control & 100W & 200W & 300W \\
\hline C & $63.41 \pm 0.024$ & $61.90 \pm 0.047$ & $59.18 \pm 0.038$ & $62.31 \pm 0.007$ \\
& & & & \\
h & $94.10 \pm 0.009$ & $94.62 \pm 0.006$ & $95.21 \pm 0.003$ & $94.74 \pm 0.006$ \\
& & & & \\
TCD & - & $7.81 \pm 1.110$ & $30.37 \pm 1.790$ & $9.45 \pm 1.200$ \\
BI & $127.37 \pm 4.613$ & $193.33 \pm 0.650$ & $257.22 \pm 2.174$ & $230.33 \pm 0.826$ \\
& & & & \\
PH & $6.17 \pm 0.120$ & $6.12 \pm 0.170$ & $6.11 \pm 0.230$ & $6.14 \pm 0.150$ \\
& & & &
\end{tabular}

In this study, Effects of ultrasound treatment on the color attributes in the pumpkin juice was evaluated (Table1). As shown in Table 1, The main results suggest that ultrasound did not induce significant changes in $\mathrm{C}$ and $h$ values, but did induce significant changes in TCD, BI, Wang et al, by studying the application of ultrasound in strawberry juice, observed that the technique was responsible for an increase in the parameter TCD ${ }^{[16]}$. Similarly, in Souza et al study, sonication significantly affected all color parameters evaluated in cape gooseberry - Physalis peruviana juice ${ }^{[17]}$. This may be due to the inhibition or activation of chromatic aberration-related enzymes caused by the cavitation effect during the ultrasonic process under extreme physical conditions, thus measuring this result ${ }^{[18,19,20]}$. At the same time, the use of ultrasound can cause greater cell disruption, leading to the release of intracellular compounds, which can serve as substrates for oxidative processes and thereby affect the color of the final product ${ }^{[21]}$.

Acidity is an important parameter of juice quality. It affects not only the taste of the juice but also the possibility of the development of microorganisms ${ }^{[22]}$. It can be seen from the figure that there is no significant change in the $\mathrm{pH}$ of untreated pumpkin juice and ultrasonic treated Cucurbita pepo, which is consistent with the result of Starek et al. 's study on the influence of ultrasonic treatment on the $\mathrm{pH}$ of tomato juice ${ }^{[22]}$. The effect of sonication on $\mathrm{pH}$ of juice have been reported also by other authors-Bhat et al and Abid et al ${ }^{[23,24]}$. These results show that the ultrasound treatment does not change the $\mathrm{pH}$ quality of pumpkin juice.

\subsection{Influence of ultrasonic technology on chlorophyll content of Cucurbita pepo}

It can be seen from Figure 2. that the total chlorophyll content in Cucurbita pepo decreases with the increase of ultrasonic power. With the increase of ultrasonic power, the total chlorophyll content in Cucurbita pepo decreases, which may be due to the energy and cavitation effect in ultrasonic, which destroys the cellular structure and decomposes unsteadily after the release of chlorophyll, leading to the decrease of chlorophyll content. If you want to better retain chlorophyll, ultrasonic power should not be too large. This result is related to Ordnonez-Santos et al. had the opposite effect on the carotenoid content of Cape
Gooseberry Juice after ultrasonic treatment ${ }^{[25]}$. This study results indicated that ultrasonic wave could inhibit the loss of fruit and vegetable quality to a certain extent. The specific influencing mechanism needs further study and proof.

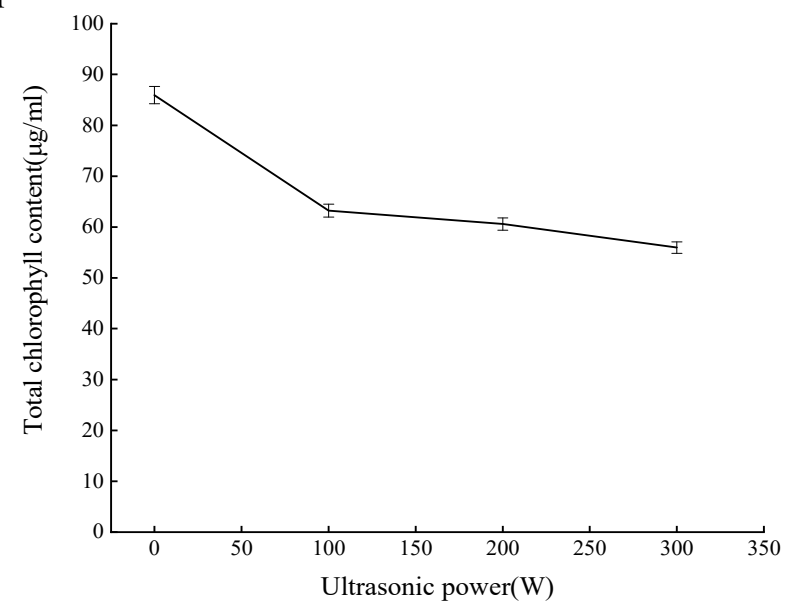

Figure 2. Influence of ultrasonic technology on chlorophyll content of Cucurbita pepo

\section{Conclusion}

In this study, the bactericidal effect, visual color, total chlorophyll content and $\mathrm{pH}$ value of Cucurbita pepo juice were evaluated by ultrasonic treatment. After ultrasonic treatment, $\mathrm{C}, \mathrm{h}$ and $\mathrm{pH}$ values did not change significantly, TCD and BI increased significantly, but total chlorophyll content decreased significantly. The results show that ultrasonic treatment is helpful to improve the quality of pumpkin juice to a certain extent. In the further study, to improve the technical parameters, it is expected to replace the hot processing technology.

\section{Reference}

1. Zdunić, Gordana, Menković, Nebojša, Jadranin, Milka, Novaković, Miroslav, Savikin, Katarina P, Živković, Jelena Č. Phenolic compounds and carotenoids in pumpkin fruit and related traditional products[J]. Institute of Chemistry, Technology and Metallurgy, 70(2016):429-433.

2. S Sharma, $\mathrm{T} V \mathrm{R}$ Rao. Nutritional quality characteristics of pumpkin fruit as revealed by its biochemical analysis[J]. Int Food Res J, 20(2013):2309-2316.

3. C H Azevedo-Meleiro, D B Rodriguez-Amaya. Qualitative and quantitative differences in carotenoid composition among Cucurbita moschata, Cucurbita maxima, and Cucurbita pepo[J]. J Agric Food Chemistry, 55(2007):4027-4033.

4. C Kurz, R Carle, A Schieber. HPLC-DAD-MSn characterisation of carotenoids from apricots and pumpkins for the evaluation of fruit product authenticity[J]. Food Chemistry, 110(2008):522-530.

5. A Nawirska-Olszanska, A Biesiada, A, SokolLetowska, A Z Kucharska. Characteristics of organic acids in the fruit of different pumpkin species[J]. 
Food Chemistry, 148(2014):415-419.

6. C L Zhou, W Liu, J Zhao, C Yuan, Y Song, D Chen, Y Y Ni, Q H Li. The effect of high hydrostatic pressure on the microbiological quality and physicalchemical characteristics of pumpkin (Cucurbita maxima Duch.) during refrigerated storage $[\mathrm{J}]$. Innov Food Sci Emerg Technol. 21(2014):24-34.

7. M Y Kim, E J Kim, Y N Kim, C Choi, B H Lee. Comparison of the chemical compositions and nutritive values of various pumpkin (Cucurbitaceae) species and parts[J]. Nutr Res Pract, 6 (2012):21-27.

8. X Li, L Zhang, Z Peng. The Impact of Ultrasonic Treatment on Blueberry Wine Anthocyanin Color and its In-vitro Anti-Oxidant Capacity[J]. Food Chemistry, 333(2020):127455.

9. V Santhirasegaram, Z Razali, C Somasundram. Effects of thermal treatment and sonication on quality attributes of Chokanan mango (Mangifera indica L.) juice[J]. Ultrasonics Sonochemistry, 20(2013):12761282.

10. W F Gomes, B K Tiwari, Ó Rodriguez, E S de Brito. Effect of ultrasound followed by high pressure processing on prebiotic cranberry juice[J]. Food chemistry, 218(2017):261-268.

11. R M Aadil, X A Zeng, Z H Zhang, M S Wang. Thermosonication: A potential technique that influences the quality of grapefruit juice[J]. International Journal of Food Science \& Technology, 50(2015):1275-1282.

12. P Khandpur, P R Gogate. Understanding the effect of novel approaches based on ultrasound on sensory profile of orange juice[J]. Ultrasonics Sonochemistry, 27(2015):87-95.

13. D I Arnon. Copper enzymes in isolated chloroplasts. polyphenoloxidase in Beta vulgaris[J]. Plant Physiology, 24(1949):1-15.

14. [14] L E Ordóñez-Santos, J Martínez-Girón, M EArias-Jaramillo. Effect of ultrasound treatment on visual color, vitamin $\mathrm{C}$, total phenols, and carotenoids content in Cape gooseberry juice[J]. Food Chemistry, 233(2017):96-100.

15. L M Carrillo-Lopez, I A Garcia-Galicia, J M TiradoGallegos et al. Recent advances in the application of ultrasound in dairy products: Effect on functional, physical, chemical, microbiological and sensory properties[J]. Ultrasonics Sonochemistry, 73(2021): 105467.

16. J Wang, SK Vanga, V Raghavan. High-intensity ultrasound processing of Kiwifruit juice: Effects on the ascorbic acid, total phenolics, flavonoids and antioxidant capacity[J]. LWT, 107(2019):299-307.

17. Francisca das Chagas do Amaral Souza a, A Lgsm, A Kdob et al. Thermosonication applied on camu-camu nectars processing: Effect on bioactive compounds and quality parameters[J]. Food and Bioproducts Processing, 116(2019):212-218.

18. T J Mason, E Joyce, S S Phull, J P Lorimer. Potential uses of ultrasound in thebiological decontamination of water[J]. Ultrason Sonochem, 10(2003):319-323.

19. T G Leighton. What is ultrasound? [J]. Prog Biophys Mol Biol, 93(2007):3-83.

20. A R Jambrak, V Lelas, Z Herceg, M Badanjak, Z Werner. Application of high-power ultrasound in drying of fruits and vegetables | Primjenaultrazvukavisokesnage u sušenjuvoc'aipovrc'a, Kem. U Ind, Chem. Chem. Eng. 59(2010):169-177.

21. J Wang, S K Vanga, V Raghavan. High-intensity ultrasound processing of kiwifruit juice: Effects on the microstructure, pectin, carbohydrates and rheological properties. Food Chemistry, 313(2020)126121.

22. A Starek, Z Kobus, A Sagan. Influence of ultrasound on selected microorganisms, chemical and structural changes in fresh tomato juice[J]. Scientific Reports, 11(1) 2021.

23. R Bhat, N S B C Kamaruddin, L Min-Tze, A A Karim. Sonication improves kasturi lime (Citrus microcarpa) juice quality. Ultrason. Sonochem, 18(2011):12951300.

24. M Abid et al. Effect of ultrasound on different quality parameters of apple juice. Ultrason Sonochem, 20(2013):1182-1187.

25. L Eduardo Ordonez-Santos, J Martinez-Giron, M Enith Arias-Jaramillo. Effect of ultrasound treatment on visual color, vitamin $\mathrm{C}$, total phenols, and carotenoids content in Cape gooseberry juice[J]. Food Chemistry, 233(2017):96-100. 